\title{
AN APPRAISAL OF CORPORATE WORKING FUND REQUIREMENTS*
}

\author{
Eugene C. Yehle \\ University of Michigan
}

The General oBJective of this study is to appraise the factors which operate through time to bring about changes in the fund requirements of a selected list of companies. ${ }^{1}$ Included among the factors which are considered are: sales volume, price levels, business conditions, inventory valuation methods, and changes in scale of operations.

A more specific objective is to examine the utility of sales volume as an index of working fund requirements. In other words, we seek to answer the question: Do the current assets of a company historically fluctuate with sales volume in a manner which is sufficiently stable to permit a generalization of its demand for funds?

The scatter diagram or correlation chart is used in the analysis with sales on the horizontal axis and current assets on the vertical axis. For the several current assets-cash, accounts receivable, and inventories-a model is developed which represents the theoretical relationship that each asset is expected to bear to sales. Actual data obtained from corporate reports to stockholders covering years from 1930 to 1948 are then compared to these models. In most cases the data are first adjusted for price changes.

The behavior patterns of corporate financial data generally conformed to the theoretical models. Particularly noteworthy were the indications of minimum or base stocks in the inventory-sales relationships, which suggest that the well-known fluctations in stocksales ratios may be a natural volume effect rather than a purely cyclical phenomenon.

On the average, the current assets, individually and in total, varied directly and linearly with sales. The year-to-year movements of these variables often departed from the average pattern, however, because of changing economic conditions, dynamic business

* A dissertation completed at the University of Michigan in 1950.

1. The companies are: Allied Stores Corporation, Consumers Power Company, Detroit Edison Company, J. C. Penney Company, Republic Steel Company, and Youngstown Sheet and Tube Company. 
expansion, and miscellaneous temporal disturbances. These departures were generally magnified rather than subdued by the price adjustments.

In most instances the short-term fluctuations were large enough to prohibit the generalization of working-fund requirements as a function of sales. Where they were small, the current assets varied almost proportionately with sales, that is, there was little if any fixed element among the current assets, and therefore an almost one-to-one correspondence seemed to exist between the percentage changes of assets and sales.

It appears that corporate self-analysis of current asset behavior is not likely to be as successful as the self-analysis of cost behavior. Where asset-sales relationships are sufficiently stable to permit a generalization of typical working fund requirements, an analysis simply of ratio trends will, in many cases, give as satisfactory results as a scatter-diagram analysis. 